\title{
Surface Modification of Aliphatic Polyester to Enhance Biocompatibility
}

\author{
Yazhong $\mathrm{Bu}^{1 \dagger}$, Junxuan $\mathrm{Ma}^{2,3+}$, Jianzhong $\mathrm{Be}^{1}$ and Shenguo Wang ${ }^{1 *}$ \\ ${ }^{1}$ Beijing National Laboratory for Molecular Sciences, State Key Laboratory of Polymer Physics and Chemistry, Institute of \\ Chemistry, Chinese Academy of Sciences, Beijing, China, ${ }^{2}$ Orthopedic Research Institute, The First Affiliated Hospital of Sun \\ Yat-sen University, Guangzhou, China, ${ }^{3}$ Guangdong Provincial Key Laboratory of Orthopedics and Traumatology, \\ Guangzhou, China
}

Aliphatic polyester is a kind of biodegradable implantable polymers, which shows promise as scaffolds in tissue engineering, drug carrier, medical device, and so on. To further improve its biocompatibility and cell affinity, many techniques have been used to modify the surface of the polyester. In the present paper, the key factors of influencing biocompatibility of aliphatic polyester were illuminated, and the different surface modification methods such as physical, chemical, and plasma processing methods were also demonstrated. The advantages and disadvantages of each method were also discussed with the hope that this review can serve as a resource for selection of surface modification of aliphatic products.

Keywords: biomedical material, aliphatic polyester, biocompatibility, surface modification, tissue engineering

Jian Yang

Anderson Oliveira Lobo,

Federal University of Piauí, Brazil

Reviewed by:

Jian Yang

Shenzhen University, China

Saeid Kargozar

Mashhad University of

Medical Sciences, Iran

*Correspondence:

Shenguo Wang

wangsg@iccas.ac.cn

†These authors have contributed equally to this work

Specialty section: This article was submitted to Biomaterials,

a section of the journal Frontiers in Bioengineering and

Biotechnology

Received: 06 February 2019 Accepted: 16 April 2019 Published: 03 May 2019

Citation:

Bu Y, Ma J, Bei J and Wang S (2019)

Surface Modification of Aliphatic

Polyester to Enhance Biocompatibility.

Front. Bioeng. Biotechnol. 7:98.

doi: 10.3389/fbioe.2019.00098

\section{INTRODUCTION}

Biodegradable polymers are defined as materials whose chemical and physical characteristics undergo deterioration and complete degradation when exposed to certain conditions, which have many important applications in medical and related fields (Rezwan et al., 2006; Nair and Laurencin, 2007). These polymers can be divided into natural biodegradable polymers and synthetic biodegradable polymers. Natural materials mainly include polysaccharides and proteins. Although they have good biocompatibility and some biofunctions, their strong immunogenic response, complex purification process and disease transmission possibility limit their applications. The synthetic biodegradable polymers can be prepared with designed routes, so they have more predictable properties and batch-to-batch uniformity. There are many synthetic biodegradable polymers, such as aliphatic polyesters, polypropylene fumarate, polyhydroxyalkanoates, and so on. Among them, aliphatic polyesters, including polyglycolide (PGA), polylactide (PLA), polycaprolactone (PCL), and their copolymers (copolylactones), are the most often used ones in tissue engineering and other bio-medical applications. Aliphatic polyesters have many advantages. Under the physiological environment, polymeric chains of the aliphatic polyesters can fracture into small pieces, with the molecular weight of the pieces decreasing from high to low. The polymeric pieces become dissolvable and finally will be absorbed or metabolized in vivo. In this way, not only the formation of foreign body reaction can be avoided, but also the secondary surgery for removing the foreign matter can also be avoided. Compared with the natural biodegradable polymers, aliphatic polyesters have the adjustable degradation rate, excellent processability, high mechanical strength, easiness to sterilization as well as good reproducibility and low price (Drury and Mooney, 2003). Therefore, aliphatic polyesters have become a kind of important biomedical 
polymer materials and have been approved as an implantable biomaterial for using in vivo by Food and Drug Administration (FDA) of many countries including China, USA and European.

\section{THE INFLUENCING FACTORS OF BIOCOMPATIBILITY OF ALIPHATIC POLYESTER}

Indeed, biocompatibility includes the interactive mechanisms relating the biomaterial with its biological environment (Lotfi et al., 2013). Since the materials interact with tissues through the cell adhesion, the biocompatibility of materials is very closely related to cell adhesion (Lotfi et al., 2013). Generally, the response of cells to a surface is dictated by the interactions of the proteins and the substrate (Kasemo and Lausmaa, 1994; Anselme, 2000; Oliveira et al., 2011). Firstly, proteins adsorb onto the surface of the material, being followed by the binding of cellular membrane receptors to the chemical groups of those proteins or even directly to the substrate exposed chemical groups. The proteins adsorption is often caused by physical (Van Der Waals force) or chemical action (ionic interaction), which happens very quickly. Then, the cell attachment is caused by the interaction between cells and some bioactive molecules, such as extracellular matrix protein, membrane proteins, cytoskeleton proteins, and so on. By controlling the cell adhesion on materials, the biocompatibility of materials can be optimized (Anselme, 2000; Veiseh et al., 2015; Chaudhuri et al., 2016). Generally speaking, the aliphatic polyester is biocompatible (Rasal et al., 2010). It will not produce toxic or carcinogenic effects in local tissues. Also the degradation products will not interfere with tissue healing (Athanasiou et al., 1996). However, for some applications, the biocompatibility is still need to be improved, because polyester intrinsically is too hydrophobic and lack reactive side-chain groups (Liu et al., 2018). Given that the surface of biomaterials will contact the cells before all other parts, the properties of the surface are particularly important for the cell adhesion and later the biocompatibility and these properties are summarized as follows.

\section{Wettability}

Wettability, also known as the hydrophilicity and hydrophobicity, will influence the cell attachment and protein absorption. The cell adhesion is induced by the protein and mediated by receptors on the cell membrane. In the cell adhesion process, the proteins are firstly absorbed onto the surface of the material, after which cellular membrane receptors are bound to proteins' chemical groups or directly to the chemical groups of the substrate (Kasemo and Lausmaa, 1994). Generally, hydrophobic surfaces will display a better affinity for proteins (Lampin et al., 1997; Yousefi et al., 2018). Therefore, the surface of the material must have hydrophobicity to absorb protein to help the recognition (Hynes, 1992). However, the hydrophilic surfaces possess a higher affinity toward the cells. A number of studies have shown that enhancing the hydrophilic properties of polymers leads to increased cell spreading and adhesion (Lee and Lee, 1993; Allen et al., 2006). As a result, keeping a balance between hydrophobicity and hydrophilicity is vital to ensure the protein adsorption as well as the cell growth (Good et al., 1998; Wang Y. W. et al., 2003).

\section{Electric Properties}

The cell membrane is negative (Wen et al., 2016). So generally positive materials are good for cell adhesion and negative surface will have charge repulsion with cells (Steele et al., 1995; Hoshiba et al., 2018). However, there are reports about a newborn rat calvaria bone osteoblasts adhering in both positive and negative surface of the polystyrene ion exchange resin microspheres (Gao et al., 1998), in which protein adsorption and cell migration can be greatly enhanced. Still the data showed that different kinds of charged surfaces led to obviously different cell morphology. So, the electric properties of the materials, including the types and densities, have great influence on the cell adhesion behavior (Shirazi et al., 2016; Kuo and Rajesh, 2017).

\section{Surface Free Energy}

Surface free energy can affect polar molecules such as water and protein and high surface free energy of the material is more advantageous to cell adhesion and spreading (Vandervalk et al., 1983; Nakamura et al., 2016; Ueno et al., 2019). Nakamura et al. reported that changes in surface free energy would affect polar molecules such as water and proteins. The increase in surface free energy will improve the wettability and then accelerate the cell adhesion (Nakamura et al., 2016). The surface free energy depends on chemical composition, functional groups and electric properties of material surface. These surface properties are mainly decided by the physical and chemical properties of the materials (Vanpelt et al., 1985; Nakamura et al., 2016).
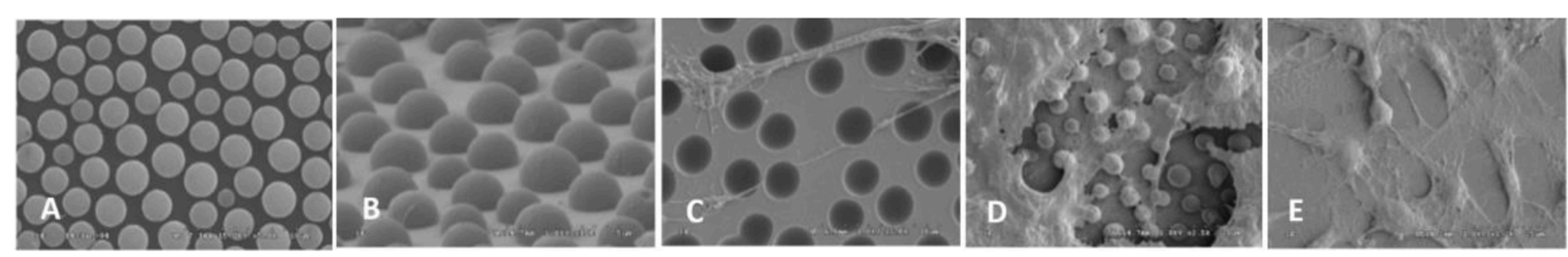

FIGURE 1 | (A) PS surface with micrometer scale pits, ×10,000; (B) PLLA surface with micrometer scale islands, $\times 10,000$; OCT-1 osteoblasts on (C) PS surface with micrometer scale pits (×5,000), (D) PLLA surface with micrometer-scale islands $(\times 2,500)$, and (E) smooth PLLA surface (×1,200) (Wan et al., 2005) [Readapted with permission from Wan et al. (2005). Copyright ${ }^{(} 2004$ Elsevier Ltd.]. 


\section{Surface Morphology Roughness}

Rough surface can enhance the cell adhesion by influencing the protein adsorption and providing larger area for cell adhesion compared with smooth surface (Lampin et al., 1997). Rough surface is good for the formation and grow of biofilm (Quirynen and Bollen, 1995). Wan et al. found that although OCT-1 osteoblast could adhere to smooth, pits-patterned, and islandpatterned surface of PLLA (Figures 1A,B), they had differences in their state of spreading. On the pits- and island-patterned surfaces (Figures 1C,D), the cells spread better than those on the smooth surface (Figure 1E). The height of cells on pit-patterned surface was obviously lower than that on the flat ones (Wan et al., 2005). It was observed that cells could adhere onto the islands and grow along the convex surface of the islands. It was also observed that the tiny pseudopodium protrusions strode from one island to another as shown in Figure 2. Because cells had more contact area and spread better on the rough surface than on the smooth ones, the OCT-1 cells had lower height on rough surfaces as was shown in Figure 1.

It could be seen that the cells could stride over the pits with $2.2 \mu \mathrm{m}$ of radius (Figure $3 \mathbf{A}$ ). The pseudopodiums of the cells could intrude inside the pits and grow along the curvature wall of the pits because the pseudopodiums of the cells had less rigidity compared to the bulk of the cells, showing "contact guidance" effects (Figure 3B). These pseudopodiums acted as anchoring points to pull the cell body, suggesting that cell is allowed to penetrate and proliferate on scaffolds with this pore size. Filopodia of cells would alter their original orientation to grow along the ridge of the pits when they reached the borders, which might be caused by "groove-ridge" induced "contact guidance". However, according to Wan, cells could not grow inside nano-scaled pits with the diameter to be $0.45 \mu \mathrm{m}$ (Curtis and Wilkinson, 1997; Wan et al., 2005).

It also found that surface morphology not only affected the cell adhesion and growth, but also the adhesion efficiency. Figure 4 demonstrated that, only around $30 \%$ of the osteoblasts could adhere on the smooth surface, while much more could adhere on rough surface (50-75\%).

However, generally speaking, the response of cells to roughness is different depending on the cell type (Chang and Wang, 2011). For osteoblasts and neurons, which is large, they might need larger surface roughness (Donoso et al., 2007). For smaller cells, like human vein endothelial cells, nanoscale of roughness could enhance cell adhesion and growth (Chung et al., 2003).
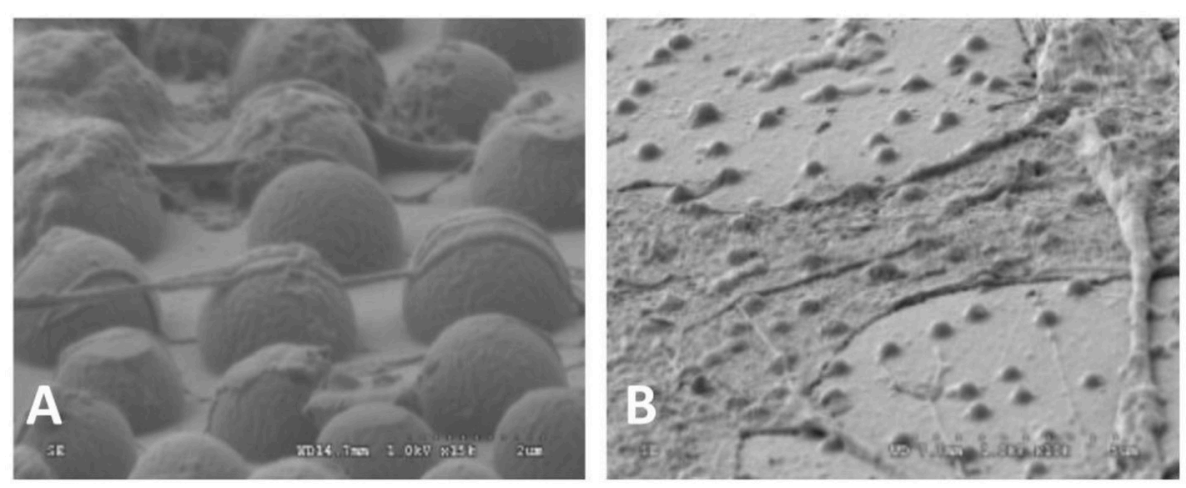

FIGURE 2 | SEM images of OCT-1 osteoblasts on PLLA surface with micro-island for 6 h: (A) the surface with micrometer scale islands, $\times 25,000$; (B) The surface with nanometer scale islands, $\times 10,000$ (Wan et al., 2005) [Readapted with permission from Wan et al. (2005). Copyright ${ }^{\circledR} 2004$ Elsevier Ltd.].
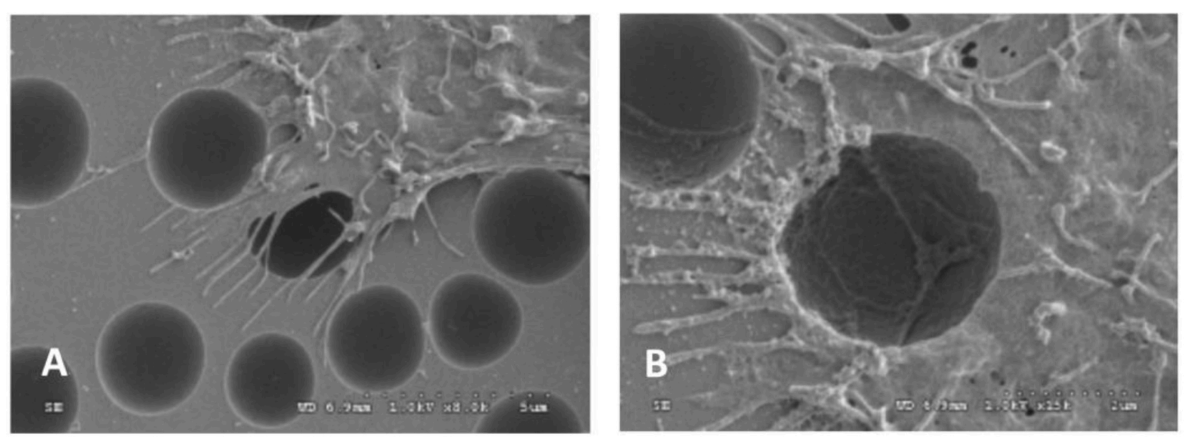

FIGURE 3 | SEM images of OCT-1 osteoblasts on PS surface with micro-pits for $6 \mathrm{~h}$ : (A) for micrometer scale pits $(2.2 \mu \mathrm{m}), \times 8,000$; (B) for micrometer scale pits $(2.2 \mu \mathrm{m}), \times 15,000$ (Wan et al., 2005) [Readapted with permission from Wan et al. (2005) Copyright ${ }^{\circledR} 2004$ Elsevier Ltd.]. 


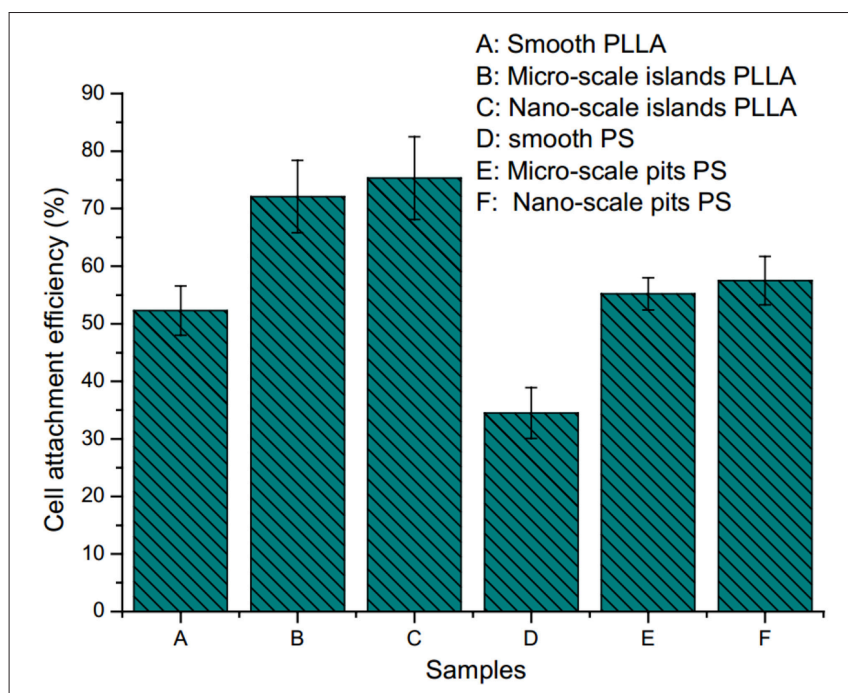

FIGURE 4 | Cell attachment efficiency on polystyrene and poly(l-lactide) surface with different sized pits and islands: (A) on smooth PLLA surface; (B) on PLLA surface with micro-scale islands; (C) on PLLA surface with nano-scale islands; (D) on smooth PS surface; (E) on PS surface with micro-scale pits; (F) on PS surface with nano-scale pits (Wan et al., 2005) [Readapted with permission from Wan et al. (2005). Copyright ${ }^{\circledR} 2004$ Elsevier Ltd.].

\section{Microgrooves}

Some natural tissues have the parallel orientation structures such as tendon, peripheral nerve and spinal cord (Figures $\mathbf{5 A - C}$ ), so the scaffolds for tissue engineering will be more promising if they can stimulate the parallel orientation structure. It was proved that by using substratum with certain shapes, alignment, or directional growth of cells in the developing brain could be induced (Hatten, 1990). By using laser ablation methods, Yao et al. fabricated micropatterned PLGA films. After being coated with collagen type I or laminin peptide (PPFLMLLKGSTR), these films showed a guidance effect on both early stage neurite outgrowth and elongation (Figures 5D-F) (Campbell and von Recum, 1989; Yao et al., 2009).

\section{Surface Structure}

Surface structures, such as walls, edges, or holes, influences the motility and spreading of cells and can be used to control the direction and localization of cell growth. Porous structure were reported to be conducive to the nutrients penetrate and cell metabolism, which was good for cell adhesion and growth (Kuo et al., 1997). Richter et al. reported that nylon net with smaller pores had larger specific surface area than those with larger pores and more cells grew on surface of materials with smaller pores. This was because cells could penetrate the nylon net with large pores, leading the failure of cell adhesion on the surface (Richter et al., 1996). So it is preferred that the scaffold for tissue engineering have porous structure and the cell adhesion behavior could be tuned by the size of the pores (Cai et al., 2002).

In summary, factors influencing the cellular affinity and then biocompatibility are summarized in Table 1. To improve the cellular affinity and biocompatibility, the modification must be used according to practical application purpose and the physicalchemical properties.

\section{SURFACE MODIFICATION OF ALIPHATIC POLYESTER}

Aiming at the above surface properties for biocompatibility, there are many ways to modify aliphatic polyester to improve the surface properties and the biocompatibility (Liu et al., 2018; Miele et al., 2018). The commonly used methods for modification are summarized in Table 2.

\section{Bulk Modification-Copolymerization}

By means of bulk modification, which is to copolymerize hydroxyl acid monomer with the molecules containing hydrophilic or charging groups (carboxyl group, hydroxyl group, amine group, subamine group, sulfonic group, amide group, etc.), surface properties of the polymers, such as crystallinity, hydrophilicity, the types and quantity of charging, and reactive groups, can be changed and optimized, finally enhancing the cell adhesion and cell affinity (Wang, 2002; He et al., 2004b; Cui et al., 2005; Wang S. G. et al., 2005; Shenguo and Jianzhong, 2011; Qiang et al., 2014; Amani et al., 2019). Many monomers and polymers can be used for the copolymerization. Poly(ethylene glycol) (PEG) is a highly biocompatible, nontoxic material with excellent hydrophilicity (Phelps et al., 2012; Rong et al., 2019). To enhance hydrophilicity of the poly(L-lactic acid) (PLLA), Chen et al. used poly(ethylene glycol) (PEG) macromolecular monomer to copolymerize with PLLA. With higher content of the ethylene glycol (EG) unit, water uptake ability of the PLLA-co-PEG copolymer (PLE) increased (Chen et al., 2002).

Aliphatic polyester lacks recognition sites for cells. By copolymerization of lactone monomer with other monomers containing pendant carboxyl groups and/or amino groups, it would be more easily for bioactive agents to immobilize on the material surface, enhancing the cell adhesion. He et al. used lactide to copolymerize malic acid (MA) with two carboxyl groups, and the hydrophilicity of resulting copolylactone (PLMA) could be tuned by altering the ratio of MA. With the increased amount of MA, the contact angles of the PLMA decreased (Figure 6) (He et al., 2003, 2004a,b). By comparing the rat 3T3 fibroblasts on the surface of PLMA with different amount of MA after 5 hours, the cells showed different morphology on the surface. PLMA (96/4) and PLMA (92/8) showed better attach efficacy than pure PLLA and PLMA (86/14) (Figure 7) (He et al., $2004 \mathrm{~b})$. One of the degradation products of PLMA, MA is a natural component of juice and also a necessary organic acid for human beings. So just like LA, MA could be metabolized and absorbed by bodies, which would not cause any side effects.

Because that the natural polymers are usually biodegradable and offer excellent biocompatibility, as well as good cell affinity, they could also be used to copolymerize with aliphatic polyesters. For example, by using the trimethylsilyl-protected (TMS) dextran as macroinitiator, Cai et al. synthesized PLA grafting dextran (PLA-g-dextran) and proved that compared PLA-g-dextran with 

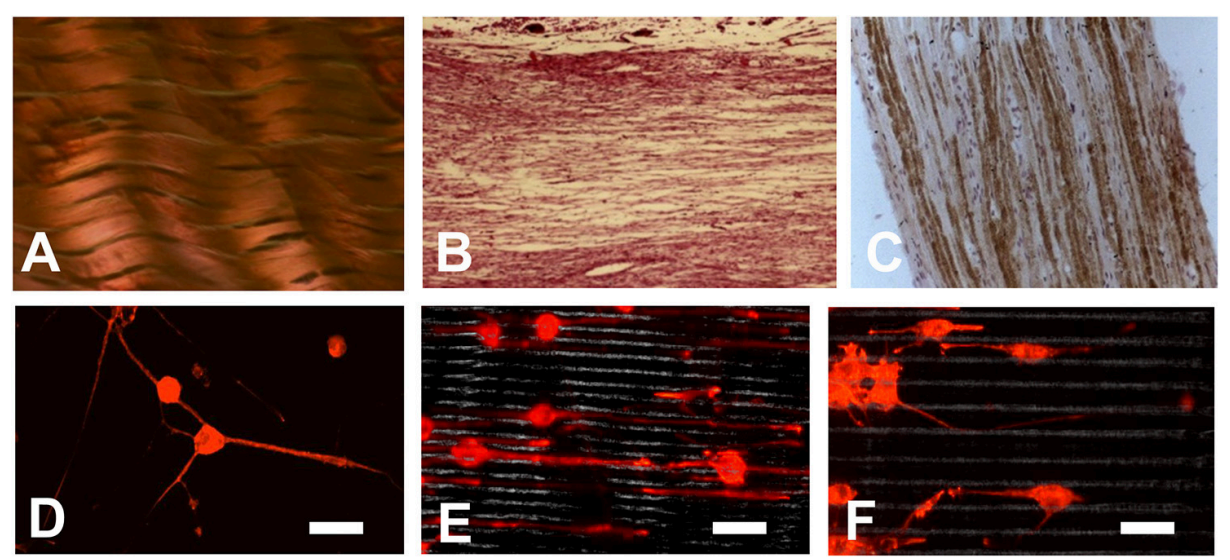

FIGURE 5 | (A-C) Some natural tissues have a parallel orientation structure: (A) Tendon; (B) Peripheral nerve; (C) Spinal cord; (D-F) Orientation of neurite growth on laminin peptide coated PLGA scaffold after 6 days culture (D) on smooth surface; (E) on scaffold with microgrooves of $5 \mu \mathrm{m}$; (F) on scaffold with microgrooves of $10 \mu \mathrm{m}$ (Yao et al., 2009). (Bar scale, $60 \mu \mathrm{m}$ ) [Readapted with permission from Ref. (Yao et al., 2009). Copyright ${ }^{\circledR} 2008$ Acta Materialia Inc. Published by Elsevier Ltd.].

TABLE 1 | The factors and influences of the material surface on biocompatibility and cell affinity.

\begin{tabular}{|c|c|}
\hline Factors & Influences \\
\hline Hydrophilicity/hydrophobicity (Yousefi et al., 2018) & Proper hydrophilicity is beneficial to cell adhesion and growth \\
\hline Surface free energy (Nakamura et al., 2016) & High surface free energy is beneficial to cell adhesion and spread \\
\hline Surface electricity (Koo et al., 2018) & Positive electricity is beneficial for attracting cells \\
\hline Surface structure (Bacakova et al., 2011) & Roughness surface is beneficial for cell adhesion and biological membrane growth \\
\hline
\end{tabular}

TABLE 2 | The surface modification methods for polylactone-type products.

\begin{tabular}{|c|c|c|}
\hline Categories & Ways & Mechanism \\
\hline \multirow[t]{2}{*}{ Chemical modification } & Bulk modification (Cui et al., 2005; Phelps et al., 2012) & Copolymerization of various monomers \\
\hline & Surface grafting (Lih et al., 2008) & Adding various functional groups to the surface \\
\hline Physical modification & Surface coating (Yang et al., 2018) & Covering the surface with biocompatible materials \\
\hline \multirow[t]{2}{*}{ Plasma modification } & Low temperature plasma treatment (Wang et al., 2004) & Changing the topological structure of surface \\
\hline & $\begin{array}{l}\text { Plasma treatment-biomolecule anchoring method (Shen } \\
\text { et al., 2009, 2010) }\end{array}$ & $\begin{array}{l}\text { Anchoring bioactive molecules on the surface by using the charged groups on the } \\
\text { surface }\end{array}$ \\
\hline
\end{tabular}

the pure PLA, the PLA-g-dextran copolymer exhibited not only better hydrophilicity but also better cell affinity (Cai et al., 2003). $\mathrm{Qu}$ et al. also reported that after grafting lactic acid onto amino groups of chitosan, a novel $\mathrm{pH}$-sensitive physically crosslinked hydrogels could be constructed (Qu et al., 1999).

\section{Surface Grafting}

After polymerization of glycolide, lactide, and caprolactone, there are still some functional groups at end of the polylactone chains. By using these functional groups, the hydrophilic groups and/or charged groups can be grafted onto surface of the aliphatic polyesters through chemical reaction to improve cell compatibility, blood compatibility as well as anticoagulation properties. Since the chemical bonding is strong and stable, a long-term modification effect can be realized.

Heparin is a natural anticoagulant substance. It is used to inhibit prothrombin activation, slow down and stop formation of the fibrin network. It can also prevent incidence of infection. Heparin has been also used to improve the anticoagulant properties of polyester. By using Michael-type addition between thiolated heparin and PLGA-PEG-PLGA diacrylate, Lih et al. developed novel heparin-conjugated polyester hydrogels. This hydrogel exhibited temperature dependent sol-gel transition behavior and might be used as injectable scaffold (Lih et al., 2008). Except for covalently immobilizing heparin on PLGA surface, Wang et al. also graft chitosan on the surface of PLGA using N(3-dimethylaminopropyl)-N-ethylcarbodiimide (EDC) and $\mathrm{N}$ hydroxysuccinimide (NHS). After grafting, the water contact angle of the modified film was greatly decreased and the blood and cell compatibility was improved (Wang X. H. et al., 2003). Compared with the surface coating method, surface grafting method will lead to tougher bonding between biofunctional molecules and the surface, which is expected to play a more and more important role in the field of biomedical applications. 
However, it is worth noting that the aliphatic polyester is lack of functional groups, of which only the end of main chains have the functional groups. The ones exposed on surface of the aliphatic polyester are even less. Even if all these functional groups are modified, the surface modification effect is still limited. On the other hand, sometimes organic solvents might be used in the chemical modification, which might cause destruction of topology structure of the surface as well as pollution of the environment.

\section{Surface Coating}

Because the different solubility of natural polymers and the synthetic polyesters, in most cases, bulk modification was carried out using synthetic polymers, which lacked biomedical functions because of the intrinsic shortcomings of synthetic polymers. In

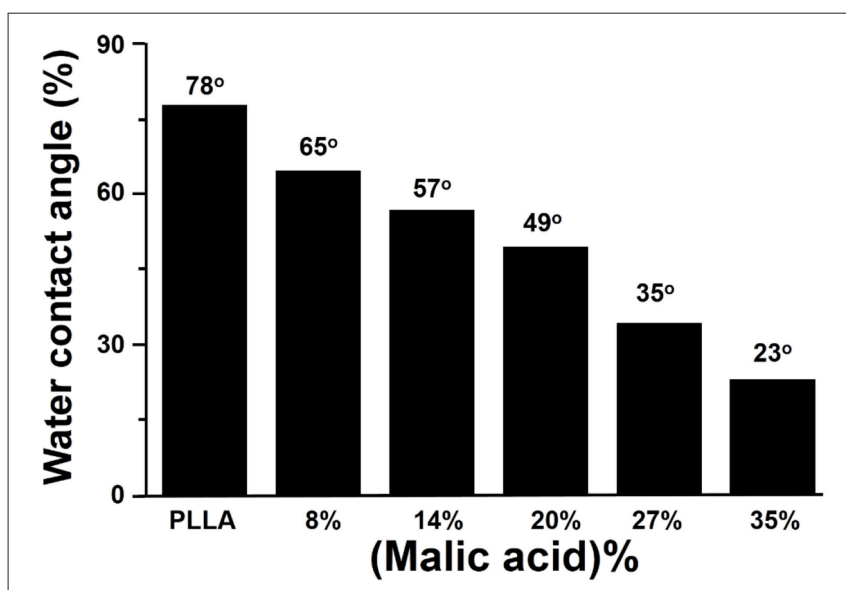

FIGURE 6 | Effect of malic acid content on water contact angle of PLMA (He et al., 2004b) [Readapted with permission from He et al. (2004b). Copyright ${ }^{(\odot)}$ 2003 Elsevier Ltd.].

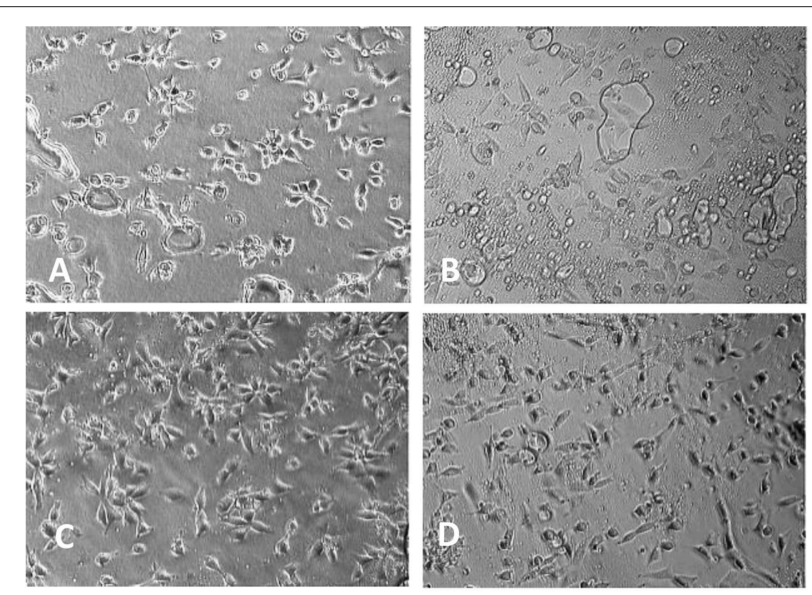

FIGURE 7 | Morphology of 3T3 mice fibroblasts cultivated on PLMA with different composition for 5 h (×150): (A) PLLA; (B) PLMA (96/4); (C) PLMA (92/8); (D) PLMA (86/14) (He et al., 2004b) [Readapted with permission from He et al. (2004b) Copyright ${ }^{(0)} 2003$ Elsevier Ltd.]. order to add some biofunctions to the polyesters, many natural biofunctional materials such as hyaluronic acid, protein, lipid, collagen, polysaccharide, peptides, and gelatin, are coated on the surface of synthetic polymers. Generally, the coating materials are prepared in solutions and the coatings were prepared by soaking, brushing, or spraying methods. Hyaluronic acid and collagen possess excellent biocompatibility and cell affinity which are the mostly used coating materials for surface modification (Yang et al., 2018). However, although surface coating method is simple and effective, this method is still a physical treatment and the coating has bonded to the surface by Van Der Waals force, which is relatively weak. Especially in the presence of water or body fluids, the coatings are easily to dissolve and break away from the surface, shortening the duration of the surface treatment (Balaji et al., 2015). Besides, some solvents may destruct the topology of polyester, causing adverse effects on cell affinity. Some coating fluids are too viscous, which might change the topology of the original surface, and could not infiltrate into materials due to their high viscosity.

\section{Plasma Modification Plasma Modification}

Plasma treatment is a straight-forward and widely used method for modifying the surface of materials to improve cell affinity of cell scaffolds (Yang et al., 2002b; Oehr, 2003). Plasma is complex system composed of neutral or excited states of atoms, molecules, free radical, electronics, ions, and radiant photon with high energy and high reactivity. It belongs to the fourth state, which is beyond the state of the solid, liquid and gas. Generally, the electromagnetic radiation, especially in ultraviolet and vacuum ultraviolet regions, is rich of plasma. By applying

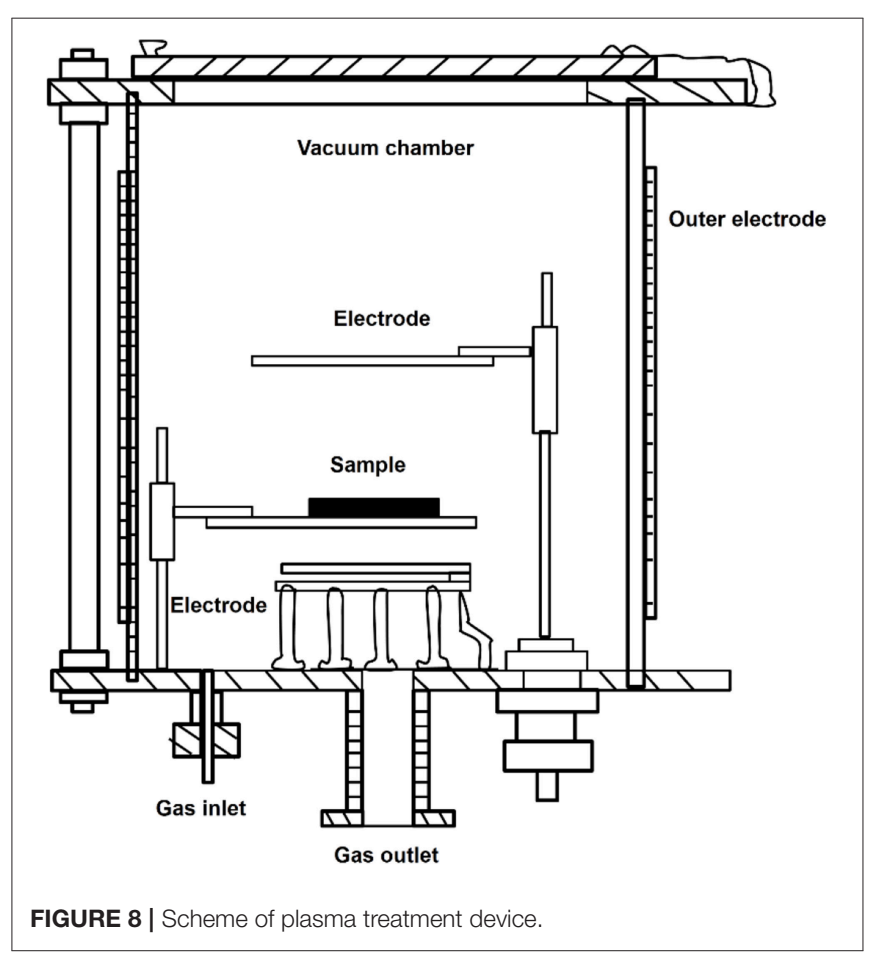


the plasma generator in Figure 8, plasma can be obtained using radio-frequency discharge in $0.1 \sim 100 \mathrm{~Pa}$. Since surface parts of the materials are exposed to energies higher than the characteristic bonding energy of polymers, these parts undergo scission reactions and form new bonding configurations on the surface (Oehr, 2003). Functional groups such as $-\mathrm{NH}_{2},-\mathrm{OH}$, and - $\mathrm{COOH}$ can be grafted by plasma treatment with non-deposition gas such as ammonia, oxygen, hydrogen oxide, and so on (Yang et al., 2002b; Oehr, 2003). Because the temperature of particles in the generator is close to or slightly higher than the room temperature, it is also called low temperature plasma.

The process for plasma treatment is relatively simple. Firstly, the generator is filled with gas that cannot be polymerized, such as methane, ammonia gas, nitrogen, oxygen, and argon. Then the sample is put into the cavity of generator; by using

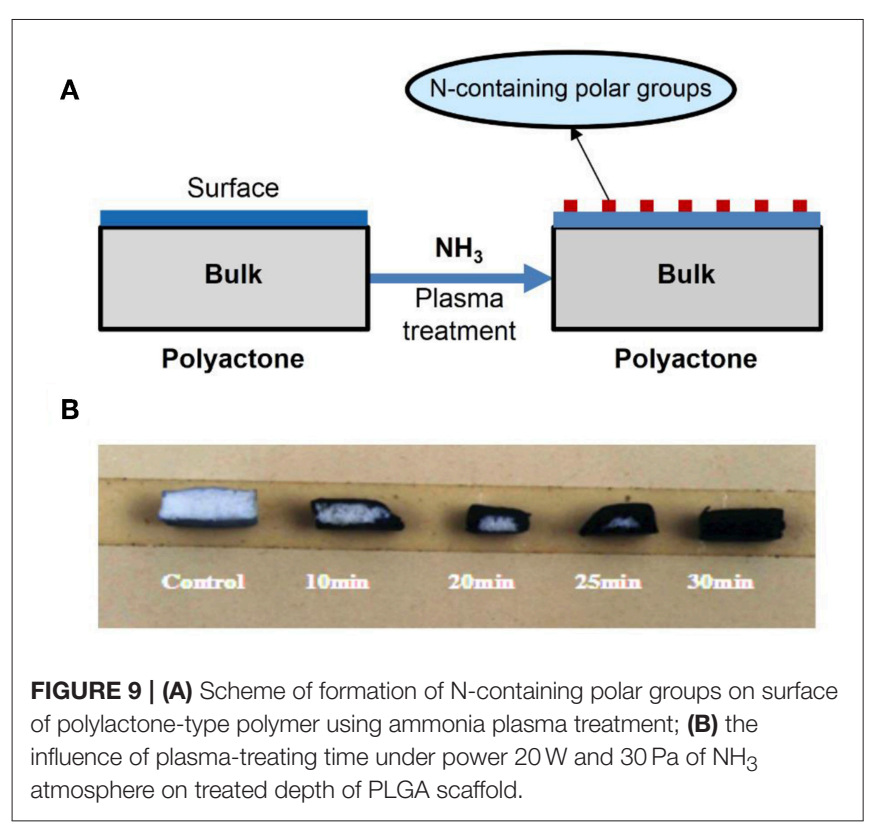

electrostatic field, plasma particles are generated, inducing molecular excitation, ionization, and chemical bond fracture on the surface. This method sculptures the surface in the range from dozens to thousands of Egypt to form new topology structure and will not cause the thermal decomposition or ablation of the material (Oehr, 2003).

The effect of plasma modification could be optimized by changing the gas, processing time, pressure and processing power. Different gas and pressure will result in the formation of functional groups with various types and properties. The plasma processing time and power lead to different processing depth, topology structure and densities of the formed functional groups (Favia and d'Agostino, 1998; Wang et al., 2004; Wang M. J. et al., 2005).

Under an ammonia atmosphere, some nitrogen-contained polar functional groups could be formed on the surface of polyester (Figure 9A). The depth of modification (Figure 9B) and the surface topology changed (Figure 10) with the increase of the plasma treatment time (Wang et al., 2004).

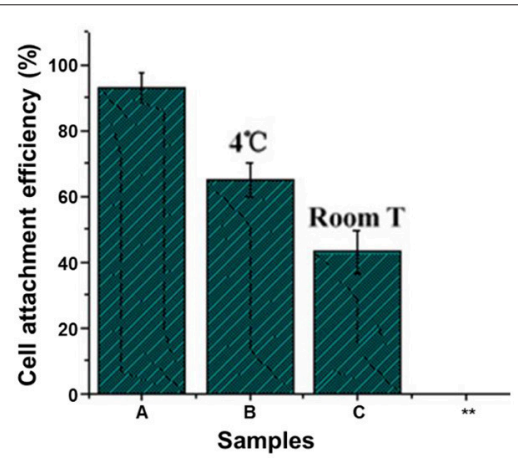

FIGURE 11 | Effect of storing temperature on adherence of mice 3T3 fibroblasts on $\mathrm{NH}_{3}$ plasma-treated PLGA films under $20.3 \mathrm{~N} / \mathrm{m}^{2}$ of shear stress for 60 min (Wang et al., 2004) (Readapted with permission from Wang et al. (2004). Copyright ${ }^{(} 2003$ Elsevier Ltd.).

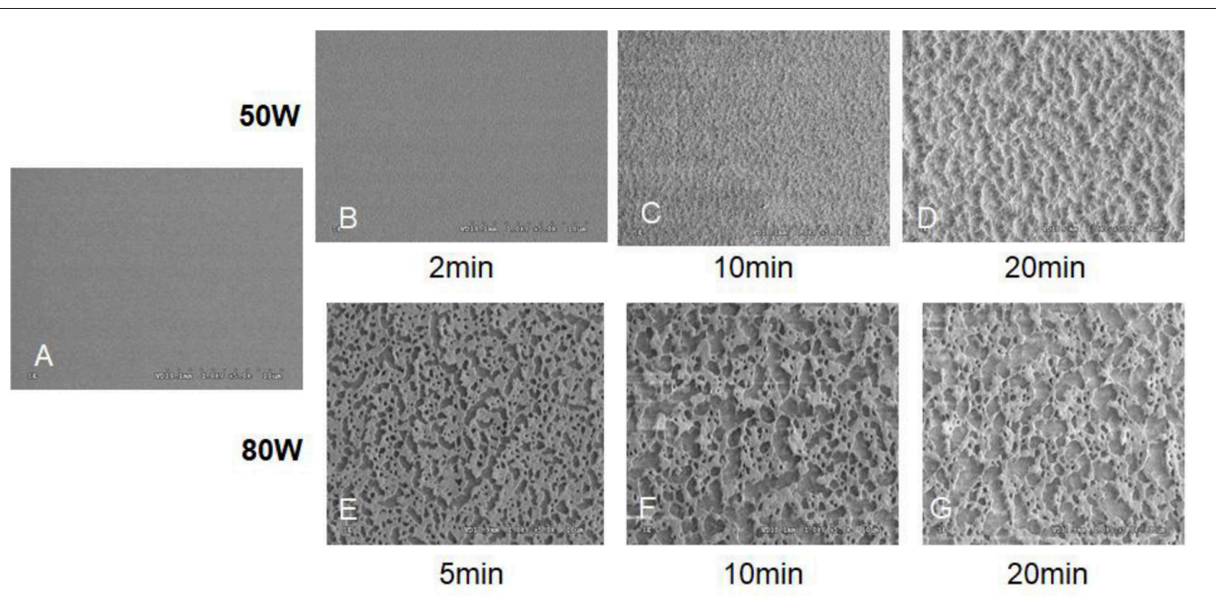

FIGURE 10 | The SEM images of control and oxygen-plasma treated PLGA surface: (A) Control; (B) $50 \mathrm{~W}, 2 \mathrm{~min}$; (C) $50 \mathrm{~W}, 10 \mathrm{~min}$; (D) $50 \mathrm{~W}, 20 \mathrm{~min}$; (E) $80 \mathrm{~W}, 5 \mathrm{~min}$; (F) 80 W, 10 min; (G) 80 W, 20 min (Wang et al., 2004) [Readapted with permission from Wang et al. (2004). Copyright ${ }^{\odot} 2003$ Elsevier Ltd.]. 


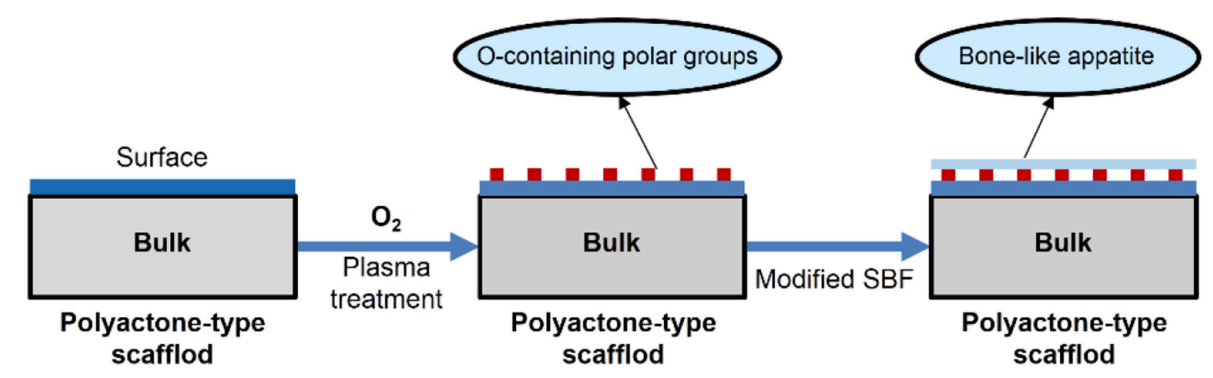

FIGURE 12 | Modification of PLGA by oxygen-plasma treatment then bone-like apatite incubation in modified SBF.

Compared with other methods, low temperature plasma is not only easier to operate but also more efficient in changing the hydrophilicity and electric properties. The method can avoid changing physical and chemical properties as well as morphology structure. It is also a green method without risk of pollution.

However, since the plasma easily moves due to the thermal action under the common temperature, the plasma on the surface would gradually migrates inside of the materials, resulting in the decreasing of functional groups on the surface and reducing attachment efficiency of the cell (Figure 11). To solve the problem, it is necessary to decrease storage time of the plasma treating product, and/or to keep the plasma treating product at low temperature (Wang et al., 2004).

\section{Plasma Treatment-co-Biomolecule Anchoring Method}

By using plasma treatment, functional groups with special physical and chemical properties can be generated, grafting other molecules or bioactive molecules. After the functional groups are bonded with other molecules and/or the large groups, the thermal moving of plasma will become difficult due to the increased volume, increasing the stability of the plasma treatment.

Yang et al. used nitrogen containing groups $\left(\mathrm{C}-\mathrm{N}^{+},-\mathrm{NH}-\right)$ which generated under ammonia atmosphere to fix collagen. After fixing the collagen, the plasma treatment was prolonged and the biocompatibility was improved (Yang et al., 2002a,b, 2003, 2004).

Wang et al. applied oxygen plasma to modify PLGA. They found that the surface roughness was improved after modification. What's more, the formed oxygen containing functional groups on the surface could adsorb bovine serum albumin during the cell culture process and mediate cell to adhere and grow on PLGA (Wang et al., 2004).

As shown in Figure 12, after PLGA was performed with plasma treatment under oxygen atmosphere, a bovine serum albumin layer can be formed on the surface of PLGA. The resulting scaffold showed enhanced cell affinity with OCT-1 cells (Qu et al., 2007).

Growth factors are bio-active molecules that can influence cell growth and other functions. Growth factor was found in platelet, adult and embryonic tissues as well as many cells which differ according to types of cells. It is also one of the three main elements for Tissue Engineering. However, growth factors have poor thermal stability and easily lose biological activity at room temperature or in water (Langer and Vacanti, 1993). To keep the biological activity of the growth factor, Shen et al. fixed alkaline fibroblast growth factor (b-FGF) onto surface of the PLGA by using the plasma treatment-growth factor anchorage technique under $\mathrm{CO}_{2}$ (Shen et al., 2008). Then they fixed rhBMP2 onto surface of the PLGA by plasma treatment under oxygen atmosphere (Shen et al., 2009, 2010). This surface treatment technique can not only prevent the plasma from migrating inside of the scaffold, but also keep biological activity of the fixed growth factor and achieve slow release of the growth factor (Shen et al., 2007).

Plasma has good penetrability. The plasma treatment is not limited to the cell scaffolds with smooth and/or rough surface but also can be used on materials with hollows and/or porous structure. However, it must be noted that when using the plasma treatment, the special plasma generator and gas are necessary, and control equipment is also expensive. Besides, the size of the treated material is restricted by the size of the equipment chamber.

\section{CONCLUSION}

To improve biocompatibility of aliphatic polyesters, copolymerization, surface coating and grafting as well as plasma treatment can be used for the surface modification of the aliphatic polyester to optimize the properties. Chemical modification can achieve long and stable effects but is limited by the co-polymerization materials and the functional groups. Physical coating method is simple and effective, but the bonding is relatively weak, especially in water. Plasma treatment is a convenient and widely used method, but the size of the treated material is restricted. The selection of modification methods should be based on biomedical application and request.

\section{AUTHOR CONTRIBUTIONS}

YB did the literature search and paper writing. JM did literature research, data analysis and helped revise the paper. JB provided suggestion on biocompatibility. SW was responsible for the whole paper design and manuscript organization. 


\section{REFERENCES}

Allen, L. T., Tosetto, M., Miller, I. S., O'Connor, D. P., Penney, S. C., Lynch, I., et al. (2006). Surface-induced changes in protein adsorption and implications for cellular phenotypic responses to surface interaction. Biomaterials 27, 3096-3108. doi: 10.1016/j.biomaterials.2006.01.019

Amani, A., Kabiri, T., Shafiee, S., and Hamidi, A. (2019). Preparation and characterization of PLA-PEG-PLA/PEI/DNA nanoparticles for improvement of transfection efficiency and controlled release of DNA in gene delivery systems. Iran. J. Pharm. Res. 18, 125-141. doi: 10.22037/ijpr. 2019.2365

Anselme, K. (2000). Osteoblast adhesion on biomaterials. Biomaterials 21, 667-681. doi: 10.1016/S0142-9612(99)00242-2

Athanasiou, K. A., Niederauer, G. G., and Agrawal, C. M. (1996). Sterilization, toxicity, biocompatibility and clinical applications of polylactic acid/polyglycolic acid copolymers. Biomaterials 17, 93-102. doi: 10.1016/0142-9612(96)85754-1

Bacakova, L., Filova, E., Parizek, M., Ruml, T., and Svorcik, V. (2011). Modulation of cell adhesion, proliferation and differentiation on materials designed for body implants. Biotechnol. Adv. 29, 739-767. doi: 10.1016/j.biotechadv.2011.06.004

Balaji, A., Jaganathan, S. K., Vellayappan, M. V., John, A. A., Subramanian, A. P., SelvaKumar, M., et al. (2015). Prospects of common biomolecules as coating substances for polymeric biomaterials. RSC Adv. 5, 69660-69679. doi: 10.1039/C5RA12693B

Cai, Q., Wan, Y. Q., Bei, J. Z., and Wang, S. G. (2003). Synthesis and characterization of biodegradable polylactide-grafted dextran and its application as compatilizer. Biomaterials 24, 3555-3562. doi: 10.1016/S0142-9612(03)00199-6

Cai, Q., Yang, J. A., Bei, J. Z., and Wang, S. G. (2002). A novel porous cells scaffold made of polylactide-dextran blend by combining phaseseparation and particle-leaching techniques. Biomaterials 23, 4483-4492. doi: 10.1016/S0142-9612(02)00168-0

Campbell, C. E., and von Recum, A. F. (1989). Microtopography and soft tissue response. J. Invest. Surg. 2, 51-74. doi: 10.3109/08941938909016503

Chang, H. I., and Wangs, Y. (2011). "Cell responses to surface and architecture of tissue engineering scaffolds," in Regenerative Medicine and Tissue Engineering - Cells and Biomaterials, ed D. Eberli (Rijeka: InTech), Chapter 27, 569-588. doi: $10.5772 / 21983$

Chaudhuri, O., Gu, L., Klumpers, D., Darnell, M., Bencherif, S. A., Weaver, J. C., et al. (2016). Hydrogels with tunable stress relaxation regulate stem cell fate and activity. Nat. Mater. 15, 326-334. doi: 10.1038/nmat4489

Chen, W. N., Yang, J., Wang, S. G., and Bei, J. Z. (2002). Synthesis and properties of poly (L-lactide)-poly (ethylene glycol) multiblock copolymers. Acta Polym. Sinica 695-698.

Chung, T. W., Liu, D. Z., and Wang, S. Y., S.S. (2003). Enhancement of the growth of human endothelial cells by surface roughness at nanometer scale. Biomaterials 24, 4655-4661. doi: 10.1016/S0142-9612(03)00361-2

Cui, W. J., Bei, J. Z., and Wang, S. G. (2005). Research development of polylactide and its copolymers. Polym. Bull. 16-23.

Curtis, A., and Wilkinson, C. (1997). Topographical control of cells. Biomaterials 18, 1573-1583. doi: 10.1016/S0142-9612(97)00144-0

Donoso, M., Méndez-Vilas, A., Bruque, J., and González-Martin, M. L. (2007). On the relationship between common amplitude surface roughness parameters and surface area: Implications for the study of cell-material interactions. Int. Biodeterior. Biodegradation. 59, 245-251. doi: 10.1016/j.ibiod. 2006.09.011

Drury, J. L., and Mooney, D. J. (2003). Hydrogels for tissue engineering: scaffold design variables and applications. Biomaterials 24, 4337-4351. doi: 10.1016/S0142-9612(03)00340-5

Favia, P., and d'Agostino, R. (1998). Plasma treatments and plasma deposition of polymers for biomedical applications. Surf. Coat. Technol. 98, 1102-1106. doi: 10.1016/S0257-8972(97)00285-5

Gao, C. Y., Li, A., and Feng, L. X. (1998). Polymer skeletal materials for tissue engineering. J. Funct. Polym. 11, 408-414.

Good, R. J., Islam, M., Baier, R. E., and Meyer, A. E. (1998). The effect of surface hydrogen bonding (acid-base interaction) on the hydrophobicity and hydrophilicity of copolymers: variation of contact angles and cell adhesion and growth with composition. J. Dispers. Sci. Technol. 19, 1163-1173. doi: $10.1080 / 01932699808913235$

Hatten, M. E. (1990). Riding the glial monorail - a common mechanism for glialguided neuronal migration in different regions of the developing mammalian. Trends Neurosci. 13, 179-184. doi: 10.1016/0166-2236(90)90044-B

He, B., Bei, J. Z., and Wang, S. G. (2003). Synthesis and characterization of a functionalized biodegradable copolymer: poly((L)-lactide-co-RS-beta-malic acid). Polymer 44, 989-994. doi: 10.1016/S0032-3861(02)00831-5

He, B., Wan, Y. Q., Bei, J. Z., and Wang, S. G. (2004a). Degradation in vitro and cell affinity of poly (L-lactide-co-beta-malic acid). Acta Polym. Sinica 693-399.

He, B., Wan, Y. Q., Bei, J. Z., and Wang, S. G. (2004b). Synthesis and cell affinity of functionalized poly(L-lactide-co-beta-malic acid) with high molecular weight. Biomaterials 25, 5239-5247. doi: 10.1016/j.biomaterials.2003.12.030

Hoshiba, T., Yoshikawa, C., and Sakakibara, K. (2018). Characterization of initial cell adhesion on charged polymer substrates in serum-containing and serumfree media. Langmuir 34, 4043-4051. doi: 10.1021/acs.langmuir.8b00233

Hynes, R. O. (1992). Integrins: versatility, modulation, and signaling in cell adhesion. Cell 69, 11-25. doi: 10.1016/0092-8674(92)90115-S

Kasemo, B., and Lausmaa, J. (1994). Material-tissue interfaces: the role of surface properties and processes. Environ. Health Perspect. 102, 41-45. doi: 10.1289/ehp.94102s541

Koo, M. A., Lee, M. H., Kwon, B. J., Seon, G. M., Kim, M. S., Kim, D., et al. (2018). Exogenous ROS-induced cell sheet transfer based on hematoporphyrin-polyketone film via a one-step process. Biomaterials 161, 47-56. doi: 10.1016/j.biomaterials.2018.01.030

Kuo, S. M., Tsai, S. W., Huang, L. H., and Wang, Y. J. (1997). Plasma-modified nylon meshes as supports for cell culturing. Artif. Cells Blood Substit. Immobil. Biotechnol. 25, 551-562. doi: 10.3109/10731199709117452

Kuo, Y. C., and Rajesh, R. (2017). Nerve growth factor-loaded heparinized cationic solid lipid nanoparticles for regulating membrane charge of induced pluripotent stem cells during differentiation. Mater. Sci. Eng. C Mater. Biol. Appl. 77, 680-689. doi: 10.1016/j.msec.2017.03.303

Lampin, M., WarocquierClerout, R., Legris, C., Degrange, M., and SigotLuizard, M. F. (1997). Correlation between substratum roughness and wettability, cell adhesion, and cell migration. J. Biomed. Mater. Res. 36, 99-108. doi: 10.1002/ (SICI) 1097-4636(199707)36:1 <99::AID-JBM12>3.0.CO;2-E

Langer, R., and Vacanti, J. P. (1993). Tissue engineering. Science 260, 920-926. doi: $10.1126 /$ science. 8493529

Lee, J. H., and Lee, H. B. (1993). A wettability gradient as a tool to study protein adsorption and cell adhesion on polymer surfaces. J. Biomater. Sci. Polym. Ed. 4, 467-481. doi: 10.1163/156856293X00131

Lih, E., Joung, Y. K., Bae, J. W., and Park, K. D. (2008). An in situ gel-forming heparin-conjugated PLGA-PEG-PLGA copolymer. J. Bioact. Compat. Polym. 23, 444-457. doi: 10.1177/0883911508095245

Liu, P. M., Sun, L., Liu, P. Y., Yu, W. Q., Zhang, Q. H., Zhang, W. B., et al. (2018). Surface modification of porous PLGA scaffolds with plasma for preventing dimensional shrinkage and promoting scaffold-cell/tissue interactions. J. Mater. Chem. B 6, 7605-7613. doi: 10.1039/C8TB02374C

Lotfi, M., Nejib, M., and Naceur, M. (2013). "Cell adhesion to biomaterials: concept of biocompatibility," in Advances in Biomaterials Science and Biomedical Applications, ed. R. Pignatello (IntechOpen). doi: 10.5772/53542

Miele, D., Rossi, S., Sandri, G., Vigani, B., Sorrenti, M., Giunchedi, P., et al. (2018). Chitosan oleate salt as an amphiphilic polymer for the surface modification of poly-lactic-glycolic acid (PLGA) nanoparticles. Preliminary studies of mucoadhesion and cell interaction properties. Mar. Drugs 16:E447. doi: $10.3390 / \mathrm{md} 16110447$

Nair, L. S., and Laurencin, C. T. (2007). Biodegradable polymers as biomaterials. Prog. Polym. Sci. 32, 762-798. doi: 10.1016/j.progpolymsci.2007.05.017

Nakamura, M., Hori, N., Ando, H., Namba, S., Toyama, T., Nishimiya, N., et al. (2016). Surface free energy predominates in cell adhesion to hydroxyapatite through wettability. Mater. Sci. Eng. C Mater. Biol. Appl. 62, 283-292. doi: $10.1016 /$ j.msec.2016.01.037

Oehr, C. (2003). Plasma surface modification of polymers for biomedical use. Nucl. Instrum. Methods Phys. Res. B 208, 40-47. doi: 10.1016/S0168-583X(03)00650-5

Oliveira, S. M., Song, W., Alves, N. M., and Mano, J. F. (2011). Chemical modification of bioinspired superhydrophobic polystyrene surfaces to control cell attachment/proliferation. Soft Matter 7, 8932-8941. doi: $10.1039 / \mathrm{clsm} 05943 \mathrm{~b}$ 
Phelps, E. A., Enemchukwu, N. O., Fiore, V. F., Sy, J. C., Murthy, N., Sulchek, T. A., et al. (2012). Maleimide cross-linked bioactive PEG hydrogel exhibits improved reaction kinetics and cross-linking for cell encapsulation and in situ delivery. Adv. Mater. 24, 64-70. doi: 10.1002/adma.201103574

Qiang, S., Shifang, L., Jing, J., Hengchong, S., and Jinghua, Y. (2014). Hemocompatibility of commodity polymers modified with chemical and biological method. Mater. China 33, 212-223. doi: 10.7502/j.issn.1674-3962.2014.04.03

Qu, X., Cui, W., Yang, F., Min, C., Shen, H., Bei, J., et al. (2007). The effect of oxygen plasma pretreatment and incubation in modified simulated body fluids on the formation of bone-like apatite on poly(lactideco-glycolide) (70/30). Biomaterials 28, 9-18. doi: 10.1016/j.biomaterials.20 06.08.024

Qu, X., Wirsen, A., and Albertsson, A. C. (1999). Synthesis and characterization of $\mathrm{pH}$-sensitive hydrogels based on chitosan and D,L-lactic acid. J. Appl. Polym. Sci. 74, 3193-3202. doi: 10.1002/(SICI)1097-4628(19991220)74:13<3193::AIDAPP23>3.0.CO;2-V

Quirynen, M., and Bollen, C. M. L. (1995). The influence of surface roughness and surface-free energy on supra-and subgingival plaque formation in man: a review of the literature. J. Clin. Periodontol. 22, 1-14. doi: 10.1111/j.1600-051X.1995.tb01765.x

Rasal, R. M., Janorkar, A. V., and Hirt, D. E. (2010). Poly(lactic acid) modifications. Prog. Polym. Sci. 35, 338-356. doi: 10.1016/j.progpolymsci.2009.12.003

Rezwan, K., Chen, Q. Z., Blaker, J. J., and Boccaccini, A. R. (2006). Biodegradable and bioactive porous polymer/inorganic composite scaffolds for bone tissue engineering. Biomaterials 27, 3413-3431. doi: 10.1016/j.biomaterials.2006.01.039

Richter, E., Fuhr, G., Muller, T., Shirley, S., Rogaschewski, S., Reimer, K., et al. (1996). Growth of anchorage-dependent mammalian cells on microstructures and microperforated silicon membranes. J. Mater. Sci. Mater. Med. 7, 85-97. doi: $10.1007 / B F 00058719$

Rong, X. F., Yang, J., Ji, Y. H., Zhu, X. J., Lu, Y., and Mo, X. F. (2019). Biocompatibility and safety of insulin-loaded chitosan nanoparticles/PLGAPEG-PLGA hydrogel (ICNPH) delivered by subconjunctival injection in rats. J. Drug Deliv. Sci. Technol. 49, 556-562. doi: $10.1016 /$ j.jddst.2018.12.032

Shen, H., Hu, X., Bei, J., and Wang, S. (2008). The immobilization of basic fibroblast growth factor on plasma-treated poly(lactide-co-glycolide). Biomaterials 29, 2388-2399. doi: 10.1016/j.biomaterials.2008.02.008

Shen, H., Hu, X., Yang, F., Bei, J., and Wang, S. (2009). The bioactivity of rhBMP-2 immobilized poly(lactide-co-glycolide) scaffolds. Biomaterials 30, 3150-3157. doi: 10.1016/j.biomaterials.2009.02.004

Shen, H., Hu, X., Yang, F., Bei, J., and Wang, S. (2010). An injectable scaffold: rhBMP-2-loaded poly(lactide-co-glycolide)/hydroxyapatite composite microspheres. Acta Biomater. 6, 455-465. doi: 10.1016/j.actbio.2009.07.016

Shen, H., Hu, X., Yang, F., Bel, J., and Wang, S. (2007). Combining oxygen plasma treatment with anchorage of cationized gelatin for enhancing cell affinity of poly(lactide-co-glycolide). Biomaterials 28, 4219-4230. doi: 10.1016/j.biomaterials.2007.06.004

Shenguo, W., and Jianzhong, B. (2011). Biodegradable polymer-A kind important biomaterial 2. Biocompatibility and surface modification of aliphatic polyester. Chin. Polym. Bull. 1-14.

Shirazi, S. F. S., Gharehkhani, S., Metselaar, H. S. C., Nasiri-Tabrizi, B., Yarmand, H., Ahmadi, M., et al. (2016). Ion size, loading, and charge determine the mechanical properties, surface apatite, and cell growth of silver and tantalum doped calcium silicate. RSC Adv. 6, 190-200. doi: 10.1039/C5RA17326D

Steele, J. G., Dalton, B. A., Johnson, G., and Underwood, P. A. (1995). Adsorption of fibronectin and vitronectin onto Primaria ${ }^{\mathrm{TM}}$ and tissue culture polystyrene and relationship to the mechanism of initial attachment of human vein endothelial cells and BHK-21 fibroblasts. Biomaterials 16, 1057-1067. doi: 10.1016/0142-9612(95)98901-P

Ueno, H., Inoue, M., Okonogi, A., Kotera, H., and Suzuki, T. (2019). Correlation between Cells-on-Chips materials and cell adhesion/proliferation focused on material's surface free energy. Colloids Surf. A Physicochem. Eng. Asp. 565, 188-194. doi: 10.1016/j.colsurfa.2018.12.059

Vandervalk, P., Vanpelt, A. W., Busscher, H. J., Dejong, H. P., Wildevuur, C. R., Arends, J. (1983). Interaction of fibroblasts and polymer surfaces: relationship between surface free energy and fibroblast spreading. J. Biomed. Mater. Res. 17, 807-817. doi: $10.1002 / \mathrm{jbm} .820170508$
Vanpelt, A. W. J., Busscher, H. J., Uyen, M., Weerkamp, A. H., Dejong, H. P., Arends, J., et al. (1985). Role of the surface-free energy of polymers on the adhesion of S-sanguis cells. Caries Res. 19, 181-181.

Veiseh, O., Doloff, J. C., Ma, M., Vegas, A. J., Tam, H. H., Bader, A. R., et al. (2015). Size- and shape-dependent foreign body immune response to materials implanted in rodents and non-human primates. Nat. Mater. 14, 643-651. doi: $10.1038 / \mathrm{nmat} 4290$

Wan, Y. Q., Wang, Y., Liu, Z. M., Qu, X., Han, B. X., Bei, J. Z., et al. (2005). Adhesion and proliferation of OCT-1 osteoblast-like cells on micro- and nano-scale topography structured poly (L-lactide). Biomaterials 26, 4453-4459. doi: 10.1016/j.biomaterials.2004.11.016

Wang, M. J., Chang, Y. I., and Poncin-Epaillard, F. (2005). Acid and basic functionalities of nitrogen and carbon dioxide plasma-treated polystyrene. Surf. Interface Anal. 37, 348-355. doi: 10.1002/sia.2029

Wang, S. G. (2002). Cells scaffold in tissue engineering. Chin. J. Rehab. Theory Pract. 267-269.

Wang, S. G., Cui, W. J., and Bei, J. Z. (2005). Bulk and surface modifications of polylactide. Anal. Bioanal. Chem. 381, 547-556. doi: 10.1007/s00216-004-2771-2

Wang, X. H., Li, D. P., Wang, W. J., Feng, Q. L., Cui, F. Z., Xu, Y. X., et al. (2003), Covalent immobilization of chitosan and heparin on PLGA surface. Inter. J. Biol. Macromol. 33, 95-100. doi: 10.1016/S0141-8130(03)00072-2

Wang, Y. Q., Qu, X., Lu, J., Zhu, C. F., Wan, L. J., Yang, J. L. et al. (2004). Characterization of surface property of poly(lactide-coglycolide) after oxygen plasma treatment. Biomaterials 25, 4777-4783. doi: 10.1016/j.biomaterials.2003.11.051

Wang, Y. W., Wu, Q., and Chen, G. Q. (2003). Reduced mouse fibroblast cell growth by increased hydrophilicity of microbial polyhydroxyalkanoates via hyaluronan coating. Biomaterials 24, 4621-4629. doi: 10.1016/S0142-9612(03)00356-9

Wen, J., Weinhart, M., Lai, B., Kizhakkedathu, J., and Brooks, D. E. (2016). Reversible hemostatic properties of sulfabetaine/quaternary ammonium modified hyperbranched polyglycerol. Biomaterials 86, 42-55. doi: 10.1016/j.biomaterials.2016.01.067

Yang, J., Bei, J. Z., and Wang, S. G. (2002a). Enhanced cell affinity of poly (D,Llactide) by combining plasma treatment with collagen anchorage. Biomaterials 23, 2607-2614. doi: 10.1016/S0142-9612(01)00400-8

Yang, J., Bei, J. Z., and Wang, S. G. (2002b). Improving cell affinity of poly(D,Llactide) film modified by anhydrous ammonia plasma treatment. Polym. $A d v$. Technol. 13, 220-226. doi: 10.1002/pat.177

Yang, J., Bei, J. Z., and Wang, S. G. (2004). Study on improvement of cell affinity of polymer materials-modified poly (D, L-lactide) by anhydrous ammonia gaseous plasma. Chin. J. Repar.Reconst. Surg. 15, 269-272.

Yang, J., Wan, Y. Q., Yang, J. L., Bei, J. Z., and Wang, S. G. (2003). Plasmatreated, collagen-anchored polylactone: Its cell affinity evaluation under shear or shear-free conditions. J. Biomed. Mater. Res. A 67A, 1139-1147. doi: 10.1002/jbm.a.10034

Yang, X., Li, Y. Y., He, W., Huang, Q. L., Zhang, R. R., and Feng, Q. L. (2018). Hydroxyapatite/collagen coating on PLGA electrospun fibers for osteogenic differentiation of bone marrow mesenchymal stem cells. J. Biomed. Mater .Res. A 106, 2863-2870. doi: 10.1002/jbm.a.36475

Yao, L., Wang, S., Cui, W., Sherlock, R., O'Connell, C., Damodaran, G., et al. (2009). Effect of functionalized micropatterned PLGA on guided neurite growth. Acta Biomater. 5, 580-588. doi: 10.1016/j.actbio.2008.09.002

Yousefi, S. Z., Tabatabaei-Panah, P. S., and Seyfi, J. (2018). Emphasizing the role of surface chemistry on hydrophobicity and cell adhesion behavior of polydimethylsiloxane/TiO2 nanocomposite films. Colloids Surf. B Biointerfaces 167, 492-498. doi: 10.1016/j.colsurfb.2018.04.048

Conflict of Interest Statement: The authors declare that the research was conducted in the absence of any commercial or financial relationships that could be construed as a potential conflict of interest.

Copyright $\odot 2019 \mathrm{Bu}, \mathrm{Ma}$, Bei and Wang. This is an open-access article distributed under the terms of the Creative Commons Attribution License (CC BY). The use, distribution or reproduction in other forums is permitted, provided the original author(s) and the copyright owner(s) are credited and that the original publication in this journal is cited, in accordance with accepted academic practice. No use, distribution or reproduction is permitted which does not comply with these terms. 